\title{
Acoustically controlled auditory training in children with speech disfluency: a case report
}

\author{
Priscila Biaggi Alves de Alencar ${ }^{1,2}$ \\ https://orcid.org/0000-0002-8842-366X \\ Priscila de Araújo Lucas ${ }^{1,2}$ \\ https://orcid.org/0000-0002-8653-6441 \\ Edilamar De Bortoli ${ }^{1}$ \\ https://orcid.org/0000-0001-6978-3101 \\ Luiza Maria Bernert ${ }^{1}$ \\ https://orcid.org/0000-0002-3876-284X \\ Letícia Paola Rodrigues ${ }^{2}$ \\ https://orcid.org/0000-0002-1532-2606
}

Fátima Cristina Alves Branco-Barreiro ${ }^{1}$ https://orcid.org/0000-0003-3834-8208

Faculdade Conhecimento e Ciência FCC, Belém, Pará, Brasil.

Centro Universitário de Várzea Grande UNIVAG, Várzea Grande, Mato Grosso, Brasil.

Conflict of interests: Nonexistent

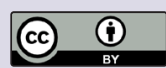

Received on: May 5, 2020 Accepted on: September 17, 20

Corresponding address:

Priscila de Araújo Lucas

Avenida Bosque da Saúde 841, apto123 -

Bairro: Bosque da Saúde

CEP:78050-070 - Cuiabá, Mato Grosso, Brasil

E-mail: prilucas@hotmail.com

\section{ABSTRACT}

The purpose of this study was to verify the effect of the acoustically controlled auditory training on the speech fluency of children diagnosed with developmental stuttering. Two patients were submitted to speech fluency evaluation, basic audiological assessment, and central auditory processing assessment, before and after the intervention with the digital platform. Two male individuals (P1 and P2) participated in the research. They were respectively 8 and 9 years old, both were right-handed, native Brazilian Portuguese speakers, diagnosed with developmental stuttering, P1 presenting a moderate, and P2, a mild-to-moderate degree. There was an improvement in some auditory skills. However, there was no improvement in the speech fluency pattern in neither of the cases studied.

Keywords: Stuttering; Hearing Disorders; Rehabilitation 


\section{INTRODUCTION}

Speech perception and production are related events, in which the appreciation of the frequency, intensity, and duration of the sounds works as a basis to develop hearing and language. Thus, producing intelligible speech depends, in great part, on the abilities to process the paradigms of the acoustic spectrum and speech prosody of the interlocutor ${ }^{1}$.

In this sense, verbal fluency can be defined as the continuous and smooth flow of speech resulting from a harmonious integration between the neural processes involved both in language and in motor action ${ }^{2}$. The fluent person can emit effortless speech, with no ruptures during the syllabic progressions, causing in the interlocutor the perception of normal speech ${ }^{3}$.

According to the Diagnostic and Statistical Manual of Mental Disorders (DSM-5), stuttering, or fluency disorder, beginning in childhood is defined as a disturbance occurring both in normal fluency and temporal pattern of speech. It is considered inadequate for a person's age and linguistic skills.

With its complex and multidimensional character, countless factors contribute to the onset of stuttering. Biological, psychological, and social factors interact with each other in a complex manner, influencing the personal development and the social interaction of the one who stutters. Among the biological factors, the auditory skills stand out as one that influences speech fluency, as studies have shown the association between stuttering and central auditory processing (CAP), and the use of delayed auditory feedback (DAF) to treat stuttering ${ }^{4}$.

The high temporal resolution required to process speech (rapid motor control task) implies directly on the fluency of stuttering people when it is changed because this skill is related to the inhibitory and excitatory dynamic process of the movements made when producing speech ${ }^{5}$. In this regard, studies that investigated the performance of stuttering people in the CAP behavioral assessment revealed some loss, especially in the temporal tests ${ }^{6,7}$. Another study found an impairment of the temporal resolution auditory skill in $85 \%$ of the stuttering people they studied, regardless of the severity 8 .

For speech to be fluent, the symbolic systems (responsible for integrating the cognitive, linguistic, and segmental components of speech, determining the form and content of the message) and signal systems (responsible for determining the proportional duration of the syllable in the word and the sequencing order of the phonetic spaces) must be temporally balanced before the generated message reaches the motor cortex. If these systems are unbalanced, the speech flow is temporarily disrupted, causing disfluencies ${ }^{9}$. The temporal imprecision in speech perception can lead to moments of disfluency, and diminished processing skills may be related to the inability to maintain fluent speech $^{10}$.

A study with functional magnetic resonance and computerized tomography in stuttering people evidenced a functional asymmetry between the brain hemispheres in this population. Hence, one of the explanations why stuttering occurs is related to the activation for speech and language, as in fluent people such activation occurs mostly on the left side, whereas in stuttering people it takes place mostly on the right side, or diffusely. The same author also reports other aspects, related to the neurofunctional bases involved in stuttering, which influence speech fluency: low neural activation in stuttering people during speech even in the absence of the articulatory movement (silent reading), loss of speech automation control, decrease in the activity of the cerebellar circuit components, to name some ${ }^{11}$.

In this perspective, objective examinations of the central auditory function, such as P300 and the research of the suppression effect of the otoacoustic emissions (OAE), also reveal a worse performance in stuttering people when compared to the fluent ones ${ }^{12}$.

Given the above, this study hypothesizes that stuttering people have their CAP skills impaired, and that, if this functional change is identified and submitted to auditory training, there may be an improvement in the fluency of stuttering children.

Thus, attention is called to the importance of verifying the effectiveness of the intervention in the central auditory function of stuttering people, focused and personalized according to the changed auditory skill(s), as identified in the assessment.

This study aimed to verify the effect of the acoustically controlled auditory training (ACAT) on the speech fluency of children diagnosed with developmental stuttering.

\section{CASE PRESENTATION}

Initially, the project was submitted to the Research Ethics Committee (REC) of the Centro Universitário de Várzea Grande (UNIVAG), Mato Grosso, Brazil, linked to the Plataforma Brasil, having been approved under no. 98813018.3.0000.5692. After its approval and before 
beginning the data collection, those responsible for the participants in this study signed the informed consent form (ICF) and the informed assent form (IAF), once the procedures of the project had been explained.

Three patients that attended the fluency outpatient center at UNIVAG - MT and that met the inclusion criteria were invited to participate in the research. However, one of them did not adhere to the training and abandoned it after the fourth session because of difficulties to go where the research was being carried out. Hence, the sample was comprised of two patients.

The inclusion criteria for this research encompassed individuals that agreed to undergo the procedures proposed for this study, after their parents/guardians signed the ICF and IAF; that were native Brazilian Portuguese speakers; aged seven to 18 years; righthanded; diagnosed with developmental stuttering (presence of at least 3\% [three percent] of stutteringlike disfluencies [SLD]); basic audiological assessment within normality; performance below the expected in two or more CAP behavioral assessment tests; of both sexes; with no combined syndromes or cognitive deficits; who effectively participated in ACAT. It is important to highlight that, as inclusion criteria, those with the abovementioned characteristics could not have undergone any type of intervention for speech fluency or any auditory training. Individuals with neurological, auditory, behavioral, or learning changes, mental disability, genetic syndromes, psychiatric conditions, or other pertaining changes that might lead to errors in the diagnosis were excluded from the sample.

Firstly, the individuals were submitted to meatoscopy and basic audiological assessment - which comprised pure-tone threshold audiometry, speech audiometry (speech recognition threshold and speech recognition percentage index), and acoustic immittance measurements (tympanometry and measurement of the stapedial muscle acoustic reflex).

As the results of these assessments were within normality, the individuals were then submitted to CAP behavioral assessment, comprising the following tests: Synthetic Sentence Identification (SSI), Speech in Noise test (SIN), Masking-Level Difference (MLD), Pitch Pattern Sequence (PPS), Random Gap Detection Test (RGDT), and dichotic digits test (DDT).

The Dichotic Consonant-Vowel Test in free recall condition (DCVT-FR), which assesses the binaural integration skill, was conducted with the single purpose of identifying the dominant brain hemisphere for language.

The normality standard criteria for the CAP assessment tests are shown in Table 1.

Table 1. Normality standards of the central auditory processing tests

\begin{tabular}{|c|c|c|}
\hline \multicolumn{2}{|c|}{ Test } & Normality standard ${ }^{*}$ \\
\hline \multirow{2}{*}{ SSI } & SNR $0 \mathrm{~dB}$ & $\mathrm{BE} \geq 80 \%$ \\
\hline & SNR $-15 \mathrm{~dB}$ & $\mathrm{BE} \geq 60 \%$ \\
\hline SIN & & $\mathrm{BE} \geq 70 \%$ and difference with SRPI $<20 \%$ \\
\hline \multirow{2}{*}{ DCVT } & FR-Binaural integration & 8-11 years: $R E$ min. 7 \\
\hline & (right-handed) & LE min. 3 and up to 8 errors \\
\hline \multirow{4}{*}{ DDT } & & $7-8$ years: $R E \geq 85 \% / L E \geq 82 \%$ \\
\hline & Binaural integration & $\geq 9$ years: $\mathrm{BE} \geq 95 \%$ \\
\hline & Ringural conaration & 7-8 years: $B E \geq 75 \%$ \\
\hline & Dillaudal separatuor & $9-10$ years: $B E \geq 85 \%$ \\
\hline \multirow{2}{*}{ PPS } & & 8 years: $\geq 40 \%$ \\
\hline & & 9 years: $\geq 65 \%$ \\
\hline MLD & & 8-11 years: $\geq 9 \mathrm{~dB} \mathrm{HL}$ \\
\hline RGDT & & $\geq 7$ years: up to $10 \mathrm{~ms}$ \\
\hline
\end{tabular}

Captions: SSI = Synthetic Sentence Identification; SIN = Speech in Noise Test; DCVT = Dichotic Consonant-Vowel Test; DDT = Dichotic Digits test; PPS = Pitch Pattern Sequence; MLD = Masking Level Difference; RGDT = Random Gap Detection Test; SNR = Signal-to-Noise Ratio; RE = right ear; $L E=$ left ear; $B E=$ both ears; SRPI $=$ Speech Recognition Percentage Index; FR = Free Recall. 
The sample for this research comprised two male individuals ( $\mathrm{P} 1$ and $\mathrm{P} 2$ ), respectively eight and nine years old. They were both right-handed, and their performance was compatible with left hemisphere dominance, according to the DCVT-FR.

Before and after the intervention, the children were submitted to speech fluency assessment and CAP behavioral assessment.

The speech fluency assessment was performed with the Fluency Profile Assessment Protocol (FPAP). A self-expressed speech sample was collected from each participant, with the least possible amount of interruptions on the part of the researchers (the interruptions occurred when the participants, who were instructed to report about subjects of their interest and daily life, needed to be encouraged to produce speech) to obtain each participant's speech fluency profile.

The collection, conducted in a quiet environment, contained a sample with 200 (two hundred) fluent syllables. After the speech samples had been collected, they were transcribed in full - i.e., both the fluent and non-fluent syllables were considered. Once transcribed, three aspects were analyzed, based on the reference values for the speech fluency profile according to the comparative parameter by age and sex for fluent native Brazilian Portuguese speakers. These parameters take a confidence interval into account in which each result obtained must be analyzed as belonging or not to the pertaining interval.

To verify the stuttering severity, the Stuttering Severity Instrument, version 3 (SSI-3) was used, which was the one available at the service where the data were collected. This instrument enabled a score to be defined, thus identifying the degree of stuttering severity: mild, moderate, severe, or very severe, following the parameters for each age group.

In this research, the criterion used to diagnose stuttering was the presence of at least 3\% (three percent) of SLD, an internationally used diagnosis criterion, as well as the fluency parameters, described as follows: (I) rupture typology assessment, classified as stuttering-like disfluencies (SLD) or other disfluencies (ODs), present in the self-expressed discourse of the assessed subjects; (II) utterance rate (qualitative and quantitative analysis) to verify the speed rate measurement with which the person is able to produce the flow of information (Flow of Words per Minute
[WPM]) and the articulatory speed measurement (Flow of Syllables per Minute [SPM]), that is, the speed with which the person can move the speech structures; and lastly (III) the rupture frequency (qualitative and quantitative analysis), to identify the rate of ruptures in the discourse (percentage of ODs), the rate of ruptures considered suggestive of stuttering (percentage of SLDs), and the percentage of overall disfluencies present in the discourse (ODs and SLDs).

The material for the audiological and CAP assessment was:

- Audiometer, model AD229, manufactured by Interacoustics;

- Notebook RV411, manufactured by Samsung;

- Acoustic immittance meter, model AT235, manufactured by Interacoustics;

- Compact Disc containing the CAP tests in Portuguese;

- Afinando o Cérebro (Tuning the Brain) portal, for the auditory training.

The auditory training protocol had a total of eight 50-minute sessions, taking place once a week.

The ACAT protocol stimulated the following skills: auditory figure-ground (exercises with competing noise and speech), auditory closure (exercises with distorted speech signal), binaural integration, and binaural separation (with dichotic tasks). They were developed in a sound booth, with supra-aural earphones connected to an audiometer. Games from an online digital platform (Afinando o Cérebro), developed to stimulate CAP skills, were used. The activities were chosen according to each person's changed skills, identified in the behavioral assessment. During each session, more than one auditory skill was stimulated, with increasing levels of difficulty. To increase the task's difficulty level, the child's performance had to be equal or superior to $70 \%$ in the previous activity; if the performance in the task was lower than $30 \%$, the difficulty level had to be decreased. After each session, the patients and those responsible for them were instructed to use the portal daily throughout the week as home training with the games defined by the therapist, to stimulate the changed auditory skill. In this platform, it is possible to verify the patient's access and performance during the training and analyze the sample.

The training conducted is described in Figure 1: 


\begin{tabular}{|c|c|c|c|c|c|c|c|c|}
\hline \multirow{2}{*}{ SKILLS } & \multicolumn{2}{|c|}{$1^{\text {ST }}$ SESSION } & \multicolumn{2}{|c|}{$2^{\text {nd }}$ SESSION } & \multicolumn{2}{|c|}{$3^{\text {rd }}$ SESSION } & \multicolumn{2}{|c|}{$4^{\text {th }}$ SESSION } \\
\hline & P1 & P2 & P1 & P2 & P1 & P2 & P1 & P2 \\
\hline Figure-ground & $\begin{array}{c}\text { Treasure hunt } \\
\text { (level 1) }\end{array}$ & $\begin{array}{c}\text { Treasure hunt } \\
\text { (level 1) }\end{array}$ & $\begin{array}{c}\text { Treasure hunt } \\
\text { (level 1) }\end{array}$ & $\begin{array}{c}\text { Treasure hunt } \\
\text { (level 1) }\end{array}$ & $\begin{array}{c}\text { Treasure hunt } \\
\text { (level 2) }\end{array}$ & $\begin{array}{c}\text { Treasure hunt } \\
\text { (level 2) }\end{array}$ & $\begin{array}{c}\text { Treasure hunt } \\
\text { (level 2) }\end{array}$ & $\begin{array}{c}\text { Treasure hunt } \\
\text { (level 2) }\end{array}$ \\
\hline Closure & & $\begin{array}{l}\text { Airplane } \\
\text { (level 1) }\end{array}$ & & $\begin{array}{l}\text { Airplane } \\
\text { (level 1) }\end{array}$ & & $\begin{array}{l}\text { Airplane } \\
\text { (level 1) }\end{array}$ & & $\begin{array}{c}\text { Restaurant } \\
\text { (level 1) }\end{array}$ \\
\hline $\begin{array}{l}\text { Binaural } \\
\text { Separation }\end{array}$ & $\begin{array}{c}\text { Binaural } \\
\text { separation } \\
\text { numbers } \\
\text { (levels } 1 \text { to 3) }\end{array}$ & & $\begin{array}{l}\text { Binaural } \\
\text { separation } \\
\text { numbers } \\
\text { (level 4) }\end{array}$ & & $\begin{array}{c}\text { Binaural } \\
\text { separation } \\
\text { Absurd things }\end{array}$ & & $\begin{array}{c}\text { Binaural } \\
\text { separation } \\
\text { Absurd things }\end{array}$ & \\
\hline \multirow[t]{3}{*}{$\begin{array}{l}\text { Binaural } \\
\text { Integration }\end{array}$} & $\begin{array}{c}\text { Young wizards } \\
\text { (levels } 2 \text { and } \\
3 \text { ) }\end{array}$ & $\begin{array}{c}\text { Young wizards } \\
\text { (levels } 2 \text { and } \\
3 \text { ) }\end{array}$ & $\begin{array}{c}\text { Hearing } \\
\text { enigma } \\
\text { All levels } \\
\end{array}$ & $\begin{array}{c}\text { Hearing } \\
\text { enigma } \\
\text { All levels } \\
\end{array}$ & $\begin{array}{l}\text { Integration } \\
\text { children }\end{array}$ & $\begin{array}{l}\text { Integration } \\
\text { children }\end{array}$ & $\begin{array}{l}\text { Dichotic } \\
\text { hearing } \\
\text { Guessing }\end{array}$ & $\begin{array}{c}\text { Dichotic } \\
\text { hearing } \\
\text { Guessing }\end{array}$ \\
\hline & \multicolumn{2}{|c|}{$5^{\text {th }}$ SESSION } & \multicolumn{2}{|c|}{$6^{\text {th }}$ SESSION } & \multicolumn{2}{|c|}{$7^{\text {th }}$ SESSION } & \multicolumn{2}{|c|}{$8^{\text {th }}$ SESSION } \\
\hline & P1 & P2 & P1 & P2 & P1 & P2 & P1 & P2 \\
\hline Figure-ground & $\begin{array}{c}\text { Treasure hunt } \\
\text { (level 3) }\end{array}$ & $\begin{array}{c}\text { Treasure hunt } \\
\text { (level 3) }\end{array}$ & $\begin{array}{l}\text { Figure-ground } \\
\text { categorization }\end{array}$ & $\begin{array}{l}\text { Figure-ground } \\
\text { categorization }\end{array}$ & $\begin{array}{l}\text { Figure-ground } \\
\text { categorization }\end{array}$ & $\begin{array}{l}\text { Figure-ground } \\
\text { categorization }\end{array}$ & $\begin{array}{l}\text { Figure-ground } \\
\text { categorization }\end{array}$ & $\begin{array}{l}\text { Figure-ground } \\
\text { categorization }\end{array}$ \\
\hline Closure & & $\begin{array}{l}\text { Restaurant } \\
\text { (level 2) }\end{array}$ & & $\begin{array}{c}\text { Restaurant } \\
\text { (level 3) }\end{array}$ & & $\begin{array}{l}\text { Restaurant } \\
\text { (level 3) }\end{array}$ & & $\begin{array}{c}\text { Restaurant } \\
\text { (level 3) }\end{array}$ \\
\hline $\begin{array}{l}\text { Binaural } \\
\text { Separation }\end{array}$ & $\begin{array}{c}\text { Binaural } \\
\text { separation } \\
\text { Absurd things }\end{array}$ & & $\begin{array}{l}\text { Binaural } \\
\text { separation } \\
\text { Stories } \\
\end{array}$ & & $\begin{array}{l}\text { Binaural } \\
\text { separation } \\
\text { Stories } \\
\end{array}$ & & $\begin{array}{l}\text { Binaural } \\
\text { separation } \\
\text { Stories } \\
\end{array}$ & \\
\hline $\begin{array}{l}\text { Binaural } \\
\text { Integration }\end{array}$ & $\begin{array}{l}\text { Integration } \\
\text { children }\end{array}$ & $\begin{array}{l}\text { Integration } \\
\text { children }\end{array}$ & $\begin{array}{l}\text { Dichotic } \\
\text { hearing } \\
\text { Guessing } \\
\end{array}$ & $\begin{array}{l}\text { Dichotic } \\
\text { hearing } \\
\text { Guessing }\end{array}$ & $\begin{array}{l}\text { Dichotic } \\
\text { hearing } \\
\text { Guessing } \\
\end{array}$ & $\begin{array}{l}\text { Dichotic } \\
\text { hearing } \\
\text { Guessing }\end{array}$ & $\begin{array}{l}\text { Dichotic } \\
\text { hearing } \\
\text { Guessing } \\
\end{array}$ & $\begin{array}{l}\text { Dichotic } \\
\text { hearing } \\
\text { Guessing }\end{array}$ \\
\hline
\end{tabular}

Figure 1. Activities performed in each session and classified according to the auditory skill stimulated

\section{RESULTS}

The results of the disfluency and CAP assessments of the participants in the sample were descriptively and individually presented, according to the analysis that was based on the following tables.
Table 2 refers to the results of the disfluency assessments before and after the ACAT.

Table 3 presents the results of the CAP behavioral assessment before and after the ACAT.

Table 2. Results of the disfluency assessments before and after the auditory training

\begin{tabular}{|c|c|c|c|c|c|}
\hline \multirow{2}{*}{ Assessment } & & & \multicolumn{2}{|c|}{ Patient (age) } & \multirow{2}{*}{$\begin{array}{l}\text { Normality standard } \\
\text { (males) }\end{array}$} \\
\hline & & & P1 (8 years) & P2 (9 years) & \\
\hline \multirow{4}{*}{ Disfluencies } & \multirow{2}{*}{ OD } & Bef & 10 & 11 & 8 years: 8.7 to 16.7 \\
\hline & & Aft & 10 & 18 & 9 years: 11.1 to 25.1 \\
\hline & \multirow{2}{*}{ SLD } & Bef & 7 & 8 & 8 years: 0.7 to 5.9 \\
\hline & & Aft & 6 & 2 & 9 years: 1.1 to 5.7 \\
\hline \multirow{4}{*}{ Speech Rate } & \multirow{2}{*}{ WPM } & Bef & 93.2 & 109 & 8 years: 73.2 to 105.4 \\
\hline & & Aft & 91.5 & 87.07 & 9 years: 62.6 to 104.6 \\
\hline & \multirow{2}{*}{ SPM } & Bef & 148.1 & 200 & 8 years: 130.7 to 182.2 \\
\hline & & Aft & 157.8 & 150 & 9 years: 111.8 to 184.5 \\
\hline \multirow{4}{*}{ Rupture Frequency } & \multirow{2}{*}{$\%$ Disc. } & Bef & $8.5 \%$ & $9.5 \%$ & 8 years: $5.7 \%$ to $10.1 \%$ \\
\hline & & Aft & $8 \%$ & $10 \%$ & 9 years: $4.5 \%$ to $12.6 \%$ \\
\hline & \multirow{2}{*}{$\%$ SLD } & Bef & $3.5 \%$ & $3.5 \%$ & 8 years: $0.2 \%$ to $2.9 \%$ \\
\hline & & Aft & $3 \%$ & $1.50 \%$ & 9 years: $0.6 \%$ to $2.7 \%$ \\
\hline Severity & & $\begin{array}{l}\text { Bef } \\
\text { Aft }\end{array}$ & $\begin{array}{l}\text { Moderate } \\
\text { Moderate }\end{array}$ & $\begin{array}{l}\text { Mild-to-moderate } \\
\text { Moderate }\end{array}$ & $\mathrm{N} / \mathrm{A}$ \\
\hline
\end{tabular}

Captions: OD = other disfluencies; SLD = stuttering-like disfluencies; WPM = words per minute; SPM = syllables per minute; Disc. = speech discontinuity; N/A = not applicable; Bef = Before; Aft = After. 
Table 3. Results of the behavioral assessments of the central auditory processing before and after the auditory training

\begin{tabular}{|c|c|c|c|c|c|c|}
\hline \multirow{2}{*}{ Test } & & & & \multicolumn{2}{|c|}{ Patient (age) } & \multirow{2}{*}{ Normality standard* } \\
\hline & & & & P1 (8 years) & P2 (9 years) & \\
\hline \multirow{8}{*}{ SSI } & & & Bef & $70 \%$ & $50 \%$ & \multirow{4}{*}{$\mathrm{BE} \geq 80 \%$} \\
\hline & & $\mathrm{RE}$ & Aft & $70 \%$ & $90 \%$ & \\
\hline & SNR O dB & \multirow{2}{*}{ LE } & Bef & $80 \%$ & $80 \%$ & \\
\hline & & & Aft & $80 \%$ & $80 \%$ & \\
\hline & & $\mathrm{DF}$ & Bef & $30 \%$ & $50 \%$ & \multirow{4}{*}{$\mathrm{BE} \geq 60 \%$} \\
\hline & & $\mathrm{RE}$ & Aft & $70 \%$ & $70 \%$ & \\
\hline & SNR $-15 d B$ & \multirow{2}{*}{ LE } & Bef & $50 \%$ & $60 \%$ & \\
\hline & & & Aft & $60 \%$ & $60 \%$ & \\
\hline \multirow{4}{*}{ SIN } & & \multirow{2}{*}{$\mathrm{RE}$} & Bef & $72 \%$ & $60 \%$ & \multirow{4}{*}{$\begin{array}{c}\mathrm{BE} \geq 70 \% \text { and difference with } \\
\text { SRPI }<20 \%\end{array}$} \\
\hline & & & Aft & $72 \%$ & $92 \%$ & \\
\hline & & \multirow{2}{*}{ LE } & Bef & $72 \%$ & $68 \%$ & \\
\hline & & & Aft & $72 \%$ & $88 \%$ & \\
\hline \multirow{4}{*}{ DCVT } & FR_Rinaural & RF & Bef & 6 & 4 & \multirow{4}{*}{$\begin{array}{l}\text { 8-11 years: RE min. } 7 \text { / LE min. } 3 \text { and } \\
\text { up to } 8 \text { errors }\end{array}$} \\
\hline & rh -BIllaural & RE & Aft & 12 & 10 & \\
\hline & (riaht_handed) & & Bef & 5 & 7 & \\
\hline & (right-handed) & LE & Aft & 6 & 4 & \\
\hline \multirow{8}{*}{ DDT } & & & Bef & $70 \%$ & $97.5 \%$ & \multirow{4}{*}{$\begin{array}{l}7-8 \text { years: } R E \geq 85 \% / L E \geq 82 \% \\
\quad \geq 9 \text { years: } B E \geq 95 \%\end{array}$} \\
\hline & Binaural & RE & Aft & $80 \%$ & $97.5 \%$ & \\
\hline & integration & \multirow{2}{*}{ LE } & Bef & $75 \%$ & $92.5 \%$ & \\
\hline & & & Aft & $80 \%$ & $85 \%$ & \\
\hline & \multirow{4}{*}{$\begin{array}{l}\text { Binaural } \\
\text { separation }\end{array}$} & \multirow{2}{*}{$\mathrm{RDH}$} & Bef & $80 \%$ & $95 \%$ & \multirow{4}{*}{$\begin{array}{l}7-8 \text { years: } B E \geq 75 \% \\
9-10 \text { years: } B E \geq 85 \%\end{array}$} \\
\hline & & & Aft & $82.5 \%$ & $95 \%$ & \\
\hline & & \multirow{2}{*}{$\mathrm{LDH}$} & Bef & $65 \%$ & $87.5 \%$ & \\
\hline & & & Aft & $82.5 \%$ & $87.5 \%$ & \\
\hline \multirow{2}{*}{ PPS } & & & Bef & $66.6 \%$ & $90 \%$ & 8 years: $\geq 40 \%$ \\
\hline & & & Aft & $66.6 \%$ & $90 \%$ & 9 years: $\geq 65 \%$ \\
\hline \multirow{2}{*}{ MLD } & & & Bef & $12 \mathrm{~dB}$ & $16 \mathrm{~dB}$ & \multirow{2}{*}{ 8-11 years: $\geq 9 \mathrm{~dB} \mathrm{HL}$} \\
\hline & & & Aft & $12 \mathrm{~dB}$ & $16 \mathrm{~dB}$ & \\
\hline \multirow{2}{*}{ RGDT } & & & Bef & $4.25 \mathrm{~ms}$ & $6.25 \mathrm{~ms}$ & \multirow{2}{*}{$\geq 7$ years: up to $10 \mathrm{~ms}$} \\
\hline & & & Aft & $4.25 \mathrm{~ms}$ & $6.25 \mathrm{~ms}$ & \\
\hline
\end{tabular}

Captions: SSI = Synthetic Sentence Identification; SIN = Speech in Noise Test; DCVT = Dichotic Consonant-Vowel Test; DDT = Dichotic Digits test;

PPS = Pitch Pattern Sequence; MLD = Masking Level Difference; RGDT = Random Gap Detection Test; SNR = Signal-to-Noise Ratio; RE = right ear;

$\mathrm{LE}=$ left ear; $\mathrm{BE}=$ both ears; SRPI = Speech Recognition Percentage Index; FR = Free Recall; RDH = right-directed hearing; $\mathrm{LDH}=$ left-directed hearing;

Bef $=$ Before; Aft $=$ After.

\section{Patient P1, eight years old}

The performance of $\mathrm{P} 1$, eight years old, was compatible with moderate stuttering in the disfluency assessment both before and after the auditory training. As seen in Table 2, the values presented for ODs, speech rate (WPM and SPM), and rupture frequency (percentage of speech discontinuity [\% $\begin{array}{ll}\% & \text { Disc.]) }\end{array}$ are within normality standards for P1's age group. However, P1's stuttering was assessed as a moderate degree due to the amount of SLD and the combined physical concomitants, which in combination are the main factors for the diagnosis criterion.

In the CAP behavioral assessment (Table 3), P1 presented a performance below the normality standard in the SSI test (which assesses the figure-ground auditory skill), in both ears with an SNR of $0 \mathrm{~dB}$ in the assessment before the auditory training; this condition was maintained in the reassessment after the auditory training. In the SNR of $-15 \mathrm{~dB}$ in both ears before the auditory training, $\mathrm{P} 1$ presented values below the normality standard; this situation had a positive change in the assessment after the auditory training, as they reached normality standards.

In the SIN test (which assesses the auditory closure skill), the values achieved by P1 in both ears, before and after the auditory training, were within normality standards.

In the DDT (which assesses the auditory skills of binaural integration and binaural separation), P1 was below the normality standard in binaural integration in both ears, in both assessments. In binaural separation, in the right-directed hearing $(\mathrm{RDH}), \mathrm{P} 1$ remained within normality standards in both assessments; in the 
left-directed hearing (LDH), P1 reached the normality standard in the assessment after the auditory training, having improved from the assessment before the auditory training, in which the corresponding value was below the normality standard.

The DCVT-FR showed that P1 had left-hemisphere dominance for language.

In the PPS test (which assesses the temporal ordering skill), MLD (which assesses the binaural interaction skill), and RGDT (which assesses the temporal resolution skill), P1 remained within normality standards both before and after the auditory training.

P1's results regarding the auditory skills of figureground, auditory closure, temporal ordering, temporal resolution, binaural interaction, and binaural separation were within normality standards. P1's binaural integration skill, though, was not yet totally within normality standards.

\section{Patient P2, nine years old}

The performance presented by $\mathrm{P} 2$, nine years old, was compatible with mild-to-moderate stuttering in the assessment before the auditory training, and moderate, after the auditory training. As seen in Table 2, the values presented for rupture frequency concerning speech discontinuity were within normality standards for P2's age group. Regarding the SLD, P2 improved after the auditory training.

As for speech rate, regarding the WPM, while the value presented in the assessment before the auditory training may indicate that $\mathrm{P} 2$ was passing more information than the expected for his age, in the assessment after the auditory training the value reached was within the confidence interval. These findings are not considered changes because they reflect the hypothesis that it was easier for P2 to get organized in his speech. The same occurred in the SPM before the auditory training in relation to after it, since P2's articulatory speed was remarkably high before the auditory training, and within the expected for his age after it. In this regard, it should be highlighted that the data presented suggest an improvement in the parameter in question since P2's speed became more adequate.

P2's performance was compatible with moderate stuttering, despite the decrease in the number of SLD, due to the combined physical concomitants.

Concerning the CAP assessment, as presented in Table 3, P2 presented a performance below the normality standard in the SSI in the right ear, in both SNR (0 dB and $-15 \mathrm{~dB}$ ) in the assessment before the auditory training. These results were normalized after the auditory training. In the left ear, P2 presented a performance within normality standards in both assessments.

In the SIN test, P2 improved in both ears in the assessment after the auditory training (as its values were within normality standards) in relation to the assessment before the auditory training.

In the DDT, P2 remained within the normality standard for the binaural integration skill in the right ear, in both assessments; the left ear, though, presented a performance below the normality standard before and after the auditory training. In the binaural separation skill, P2 presented results within normality standards before and after the intervention.

The DCVT-FR showed that P2 had left-hemisphere dominance for language.

In the PPS, MLD, and RGDT tests, P2 remained within normality standards both before and after the auditory training.

P2's results regarding the auditory skills of figureground, auditory closure, temporal ordering, temporal resolution, binaural interaction, and binaural separation were within normality standards. On the other hand, P2's binaural integration skill was not yet totally within normality standards.

\section{DISCUSSION}

Stuttering is a high-prevalence fluency disorder. Nevertheless, it is not known yet whether there is a biological marker. The fluency profile of stuttering children is quite heterogeneous, which allows for the conclusion that stuttering does not have a single cause; instead, it results from the interaction between different physiological processes ${ }^{13}$.

The relationship between stuttering and hearing is reported by various studies that demonstrate an improvement in the stuttered speech under conditions of auditory feedback - i.e., using masking, delay auditory feedback (DAF), frequency altered feedback (FAF), or a combination of these, evidencing a strong correlation between stuttering and auditory aspects ${ }^{14-18}$.

Electrophysiological studies evidence that there is a change in the processing of the acoustic signal in stuttering people when compared with their fluent peers. However, there is no consensus in the literature ${ }^{19}$.

Nowadays, it is already known that stuttering people can have changes in their auditory skills, although there is little scientific evidence in the literature regarding 
the effectiveness of the auditory training in stuttering individuals.

In the present study, changes were found in the figure-ground, auditory closure, and binaural integration and separation skills. Studies that aimed to describe the changed auditory skills in stuttering people show various results. In some studies, a lower performance was verified on the part of the stuttering individuals in relation to the non-stuttering ones ${ }^{4,20}$.

One of the studies that observed significantly lower performance in stuttering children in the temporal auditory processing, specifically the tests of frequency pattern (Pitch Pattern Sequence [PPS]) and duration pattern (Duration Pattern Sequence), hypothesized that difficulty in adequately discriminating sound frequency, intensity, and duration can lead to a perception deficit regarding speech prosody and intonation ${ }^{4}$.

Even though the literature points out that people with fluency changes can also have changes in the auditory temporal aspects ${ }^{11}$, the children that participated in the present study had a performance within the expected in the tests that assess these skills, namely, PPS and RGDT. Hence, there was no specific intervention for the temporal auditory processing skills in the participants of this study.

One of the hypotheses for the lack of consensus in the literature regarding the performance of stuttering people in temporal auditory processing tests is the heterogeneity of the groups of stuttering individuals in each research. Furthermore, since stuttering is a multifactorial disorder with biological, psychosocial, and environmental influences, such factors can also generate inconclusive results.

The DCVT-FR has been used to infer about the hemisphere dominance for speech sounds - i.e., to verify whether there is a perceptual asymmetry for linguistic stimuli assessed with free recall. The differences between the right and left ears in the dichotic hearing verbal tests reflect the functional differences between the brain hemispheres and the stronger connection each ear has with its contralateral hemisphere ${ }^{21}$. The right ear advantage regarding correct answers in the dichotic hearing tests could be interpreted as a reflex of left-hemisphere dominance for speech and language processing ${ }^{22}$.

The brain hemispheres are asymmetrically organized - the left hemisphere is more specialized for language, and the right one is more involved with the visual and spatial components in right-handed people. Although there is in the literature the theory that stuttering people do not have a hemisphere dominance for speech, that they have inverted hemisphere dominance, or that they have bilateral hemisphere dominance ${ }^{23}$, studies such as the present one that used the CVT showed that stuttering individuals have the same hemisphere dominance pattern for language as non-stuttering people $e^{6,7,24,25}$.

Another discussion in the investigations of the auditory processing in stuttering refers to the possible relationship between the stuttering severity and the results of the auditory processing assessment. In this line of reasoning, another study ${ }^{26}$ showed that stuttering severity is directly related to the performance in nonverbal auditory processing tests, such as the frequency pattern test. Other authors also correlated the behavioral auditory processing tests with the degree of stuttering severity and did not observe any type of correlation. Nonetheless, they suggest that there is indeed a relationship between the changes in auditory processing and the manifestations of stuttering ${ }^{27}$. In the present study, it was observed that the patient that presented the highest degree of stuttering severity before the training had a greater number of changed auditory skills. Yet, no change was observed in the temporal aspects.

The results that refer to the assessment and comparison of the occurrences of disfluency in the stuttering individuals before and after the auditory training do not corroborate a national study ${ }^{28}$, which demonstrated the existence of a difference in the stuttering severity after the auditory training. It should be highlighted that, for the auditory training in this study, the researcher used the same online digital game platform to stimulate auditory skills.

Some aspects must be considered regarding the increase in P2's stuttering severity. The speech fluency assessment process considers the occurrence of disfluencies common to and typical of stuttering in the spontaneous speech task. As proposed, during the assessment the researcher must interrupt the assessed subject as little as possible to collect a reliable sample of the person's speech fluency ${ }^{28}$. In this sense, four assessment attempts were made with P2, as none of the collections reached the 200 (two hundred) fluent syllables proposed by the protocol - all the collected samples were used to make up the 200 syllables. Initially, P2 was quite timid, briefly answering the questions, with short and direct emissions. However, as the auditory training went on, P2 built a greater rapport with the therapist, which enabled his oral production 
to increase. This also led to a better fluency in the collection after the auditory training since no interruptions and questions were necessary to stimulate his spontaneous speech production. In this regard, the last collection seems to evidence his actual speech fluency profile, explaining the increase in the stuttering severity. The improvement in P2's speech rate after the auditory training stands out, which can be explained by the training of the closure and figure-ground skills with spectral degradation stimuli.

These aim for good speech recognition and discrimination in environments whose hearing conditions are not ideal, such as those with reverberation, echo, environmental noise, distant or accelerated speech. Thus, the self-perception of speech rate was favored, leading to an improvement in this communication skill. Another relevant skill to be considered is that there is a greater tendency towards tension in self-expressed speech tasks, associated with linguistic representation, and speech motor planning and execution, which implies a greater cognitive demand ${ }^{29}$. It is emphasized that such results do not indicate a worsening due to the auditory training; instead, it is an adequation of the parameter assessed, which may have occurred exactly due to the improvement in the auditory skills.

Also regarding P2's results after the auditory training, one of the hypotheses that might explain the significant decrease in SLDs is that, depending on the external factors, the fluency of the stuttering person can improve - once again denoting its intermittent character. In this sense, the effort to understand this decrease resulting from such factors seems to be an appropriate one. Authors ${ }^{30}$ proposed a model named CALMS, comprising five main components that can contribute to and/or maintain stuttering. The components are: affective (feelings, emotions, and attitudes), social (the type of listener and situation to which the person is exposed), motor (sensory-motor control of the speech movements), cognitive (thoughts and perceptions), and linguistic components (language skills and requirements, and complexity of the discourse). It seems that this decrease in the SLDs is more related to the relationship between the abovementioned components, instead of being directly related to the effect of the auditory training on his speech.

Comparing each patient's performance in the CAP test before and after the auditory training, an improvement was observed in the results of the two participants in most of the auditory skills identified as dysfunctional in the initial assessment. P1 improved in the $-15 \mathrm{~dB}$ condition of the SSI, though not in $0 \mathrm{~dB}$, which seems incoherent since the first one is harder (the speech signal is $15 \mathrm{~dB}$ weaker than the competing noise). Therefore, since these are behavioral tests and they depend on the patient's cooperation, there may have been interference of factors such as tiredness or inattention. This patient's performance remained changed in the binaural integration and separation skills. P2, in his turn, had improvements in all the changed skills after the training, except for binaural integration.

The binaural integration skill involves the maturation of upper neuronal structures, such as the corpus callosum, and requires the development of a greater number of neuronal structures for adequate neural functioning. A national study ${ }^{13}$ highlights that the presence of changes in lower levels of the auditory pathway can limit the effective processing of certain acoustic information at the cortical level. Hence, it is believed that additional therapeutic sessions could generate more effective results in the binaural integration skill.

It is worth highlighting that the use of the online digital game platform to stimulate the auditory skills had good acceptance among the patients and relatives in the home training. Another aspect that stood out was the platform's effectiveness regarding the stimulation of the auditory skills that were previously changed. However, a limitation was noted in this tool concerning the activities that should be carried out at home, as it does not enable the professionals to restrict the activities not intended for each patient according to their specific needs.

Lastly, attention is called to the limitations of this study. The sample was small due to the lack of adherence on the part of some participants, who did not regularly attend the treatment. P1 missed two sessions, whereas $\mathrm{P} 2$ had no absences. It is suggested that future investigations be made with more robust samples, administering self-perception questionnaires to the parents regarding their child's stuttering both before and after the training. Also, it is recommended that the auditory training be conducted in younger children to verify the earlier influence of this training on the speech fluency of stuttering children.

The stuttering severity was assessed with version 3 of the SSI due to convenience, as it was the one available at the service where this study was conducted. However, the SSI-4, the most updated instrument, is already available in the market. A new analysis was 
not conducted with the SSI-4, though, because the main object of study in the research was to understand whether the auditory training could change the speech fluency profile. The SSI-3 was sufficient for this purpose and made the assessment possible, besides being the instrument available at the service.

New research still needs to be conducted with the same objective of the present study, with a significant sample that adheres to all the requirements of the project, and excluding the participants with irreparable flaws (for instance, when the participant performs at home an activity not intended for them, without the supervision of the professional responsible for them), so that a relevant statistical analysis can be performed.

\section{CONCLUSION}

There was no improvement in the speech fluency pattern of the participating children after the auditory training, although an improvement was observed in the performance of their auditory skills.

\section{REFERENCES}

1. Costa JB, Ritto AP, Juste FS, Andrade CRF. Comparison between the speech performance of fluent speakers and individuals who stutter. CoDAS. 2017;29(2):e20160136.

2. Andrade CRF, Juste F. Aplicação de um teste americano de severidade da gagueira (SSI) em crianças fluentes falantes do Português brasileiro. Pró-Fono R Atual Cient. 2001;13(2):177-80.

3. Bohne AJ. Sobre paradigmas, linguagem e gagueira. Rev Fono Atual. 2000;3(14):8-13.

4. Silva R, Oliveira CMC, Cardoso ACV. Aplicação dos testes de padrão temporal em crianças com gagueira desenvolvimental persistente. Rev. CEFAC. 2011;13(5):902-8.

5. Santos JLF, Parreira LMMV. Habilidades de ordenação e resolução temporal em crianças com desvio fonológico. Rev. CEFAC. 2010;12(3):371-6.

6. Andrade NA, Gil D, Schiefer AM, Pereira LD. Processamento auditivo em gagos: análise do desempenho das orelhas direita e esquerda. Rev Soc Bras Fonoaudiol. 2008;13(1):20-9.

7. Andrade NA, Gil D, Schiefer AM, Pereira LD. Avaliação comportamental do processamento auditivo em indivíduos gagos. Pró-Fono R Atual Cient. 2008;20(1):43-8.
8. Schmidt BC. Estudo da habilidade auditiva de resolução temporal em indivíduos com gagueira [Trabalho de Conclusão de Curso]. Florianópolis (SC): Universidade Federal de Santa Catarina; 2014.

9. Gomes MJC, Scrochio EF. Terapia da gagueira em grupo: experiência a partir de um grupo de apoio ao gago. RBTCC. 2001;3(2):25-34.

10. Meyers SC, Hughes LF, Schoeny ZG. Temporalphonemic Processing Skills in Adult Stutterers and Nonstutterers. J Speech Lang Hear Res. 1989;32(2):274-80.

11. Andrade CRF. Abordagem neurolinguística e motora da gagueira. In: Fernandes FDM, Mendes BCA, Navas ALGP (orgs). Tratado de Fonoaudiologia. 2. ed. São Paulo: Roca; 2009. p.423-53.

12. Arcuri CF, Schiefer AM, Azevedo MF. Research about suppression effect and auditory processing in individuals who stutter. CoDAS. 2017;29(3):e20160230.

13. Gonçalves IC. Aspectos audiológicos da gagueira: evidências comportamentais e eletrofisiológicas [Tese]. São Paulo (SP): Universidade de São Paulo; 2013.

14. Lincoln M, Walker C. A survey of Australian adult users of altered auditory feedback devices for stuttering: use patterns, perceived effectiveness and satisfaction. Disability and Rehabilitation. 2007;29(19):1510-7.

15. Van Borsel J, Eeckhout H. The speech naturalness of people who stutter speaking under delayed auditory feedback as perceived by different groups of listeners. J Fluency Disorders. 2008;33(3):241-51.

16. Armson J, Kiefte M. The effect of SpeechEasy on stuttering frequency, speech rate, and speech naturalness. J Fluency Disord. 2008;33(2):120-34.

17. Antipova EA, Purdy SC, Blakeley M, Willians S. Effects of altered auditory feedback (AAF) on stuttering frequency during monologue speech production. J Fluency Disord. 2008;33(4):274-90.

18. Pollard R, Ellis JB, Finan D, Ramig PR. Effects of the SpeechEasy on objective and perceived aspects of stuttering: a 6-month, phase i clinical trial in naturalistic environments. J Speech Lang Hear Res. 2009;52(2):516-33.

19. Prestes R, Andrade AM, Santos RBF, Marangoni AT, Schiefer AM, Gil D. Temporal processing and long-latency auditory evoked potential in stutterers. Braz J Otorhinolaryngol. 2017;83(2):142-6. 
20. Arcuri CF. Pesquisa do efeito de supressão e do processamento auditivo [Tese]. São Paulo (SP): Universidade Federal de São Paulo; 2012.

21. Kimura D. Some effects of temporal-lobe damage on auditory perception. Lata $J$ Exp Psychol.1961;15(3):156-65.

22. Blood GW, Blood IM. Central auditory function in young stutterers. Percept Mot Skills.1996;59(3):699-705.

23. Alvarez AMMA, Balen S, Misorelli MI, Sanchez ML. Processamento auditivo central: proposta de avaliação e diagnóstico diferencial. In: Munhoz MSL, Caovilla HH, Silva MLG, Ganança MM (orgs). Audiologia clínica série otoneurologia. São Paulo: Atheneu; 2000. p.103-20.

24. Pascoinelli AT, Juste FS, Andrade CR, Schochat E, Murphy CFB. Escuta dicótica em indivíduos com gagueira: efeito do tipo de tarefa, estímulo e demanda cognitiva. In: Anais do 23 Congresso Brasileiro e 9 Congresso Internacional de Fonoaudiologia; 2015; Salvador, Bahia. Brasil: 2015.

25. Andrade CRF, Schochat E. Comparação entre os achados neurolinguísticos e neuroaudiológicos nas gagueiras. Pró-Fono $\mathrm{R}$ Atual Cient. 1999;11(2):27-30.

26. Schiefer AM, Barbosa LMG, Pereira LD. Considerações preliminares entre uma possível correlação entre a gagueira e os aspectos linguísticos e auditivos. Pró-Fono $\mathrm{R}$ Atual Cient. 1999;11(1):27-31.

27. Viléla LBFA. Eficácia do treinamento auditivo em indivíduos com gagueira [Dissertação]. Marília (SP): Universidade Estadual de São Paulo; 2019.

28. Andrade CRF. Fluência. In: Andrade CRF, Befi-Lopes DM, Fernandes FDM, Wertzner HF (orgs). ABFW: Teste de linguagem infantil nas áreas de fonologia, vocabulário, fluência e pragmática. Carapicuíba: Pró-Fono, 2011. p. 51-81.

29. Ferreira AMM. Estudos para uma proposta de feedback de suavização e prolongamento da fala da pessoa que gagueja [Tese]. São Paulo (SP): Pontifícia Universidade Católica de São Paulo; 2019.

30. Healey CE, Trautman LS, Susca M. Clinical applications of a multidimensional approach for the assessment and treatment of stuttering. CICSD. 2004;(31):40-8. 